Elsevier required licence: (C) $<2015>$. This manuscript version is made available under the CC-BY-NC-ND 4.0 license http://creativecommons.org/licenses/by-nc-nd/4.0/ 


\section{Title: Unravelling the complexities of nursing students' feedback on the clinical learning environment: A mixed methods approach}

Running Head: Students' feedback on clinical placement

Yenna Salamonson ${ }^{1}$, Bronwyn Everett ${ }^{1}$, Elizabeth Halcomb ${ }^{2,1}$, Marie Hutchinson ${ }^{3}$, Debra Jackson ${ }^{4}$, Judy Mannix ${ }^{1}$, Kath Peters ${ }^{1}$, Roslyn Weaver ${ }^{1}$

${ }^{1}$ University of Western Sydney, ${ }^{2}$ University of Wollongong, ${ }^{3}$ Southern Cross University, ${ }^{4}$ University of Technology Sydney

Email addresses

Yenna Salamonson: y.salamonson@uws.edu.au

Bronwyn Everett: b.everett@uws.edu.au

Elizabeth Halcomb: ehalcomb@uow.edu.au

Marie Hutchinson: marie.hutchinson@scu.edu.au

Debra Jackson: debra.jackson@uts.edu.au

Judy Mannix: j.mannix@uws.edu.au

Kathleen Peters k.peters@uws.edu.au

Roslyn Weaver_r.weaver@uws.edu.au

\section{Conflict of interest}

No conflict of interest has been declared by the authors.

\section{Author contributions}

DJ and YS were responsible for the study conception and design, $\mathrm{BE}, \mathrm{MH}, \mathrm{DJ}, \mathrm{JM}$ and $\mathrm{YS}$ organised the data collection and performed the data analysis. YS, BE, EH, MH, DJ, JM, KP and RW were responsible for drafting the manuscript. $\mathrm{YS}, \mathrm{BE}, \mathrm{EH}, \mathrm{MH}, \mathrm{DJ}, \mathrm{JM}, \mathrm{KP}$ and $\mathrm{RW}$ made critical revisions to the paper for important intellectual content.

\section{Acknowledgements}

We would like to thank Associate Professor Sharon Bourgeois for assisting with data collection in one of the four Australian universities.

\section{Funding}

This project received no specific grant from any funding agency in the public, commercial, or not-forprofit sectors. 


\section{Abstract}

Background: Clinical placement is an essential part of nursing education, and students' experiences on clinical placement can affect the quality of their learning. Understanding nursing students' positive and negative perceptions of clinical placement experience is therefore important. Objectives: To describe nursing students' satisfaction with their clinical placement experiences and identify any variations in satisfaction based on demographic characteristics. Design: Mixed methods-online survey with qualitative items. Setting: Four universities in Australia. Participants: Students $(n=213)$ enrolled in an undergraduate nursing degree. Methods: Between 2010 and 2012, students completed online surveys following their clinical placement experiences. The surveys included demographic questions and the Clinical Learning Environment Inventory (CLEI-19), a 19-item tool measuring students' satisfaction with clinical placement. The surveys included two open-ended questions asking students to share their most satisfying and challenging experiences while on placement. Descriptive statistics and thematic analyses were undertaken. Results: Of the 213 participants, those in health-related employment and those with English as an additional language (EAL) were less satisfied with the clinical facility and with clinical facilitator support respectively, as indicated by the CLEI-19 subscale scores. Qualitative findings showed students were positive about the opportunity to make a difference and be involved in nursing, and negative about clinical facilitator support. Nevertheless, those who were most critical in their written comments about their placement were those who only spoke English at home. Conclusions: Although the study found overall satisfaction with clinical placement, the lower satisfaction reported by students in health-related employment, and the mixed findings regarding language spoken and satisfaction, warrant further attention. 


\section{Introduction}

Clinical experience is an essential learning activity and integral for the professional development of all undergraduate nursing students. As the recruitment of nursing students into higher education continues to escalate to meet the looming global mass exit of retiring nurses from the workforce (Aiken et al., 2009), the capacity for clinical placements to meet this growing student demand is increasingly being challenged. Other factors also contributing to this demand-supply strain include the decreased numbers of hospital beds, a reluctance to accept more students due to the time and resources required to support them in an already overstretched nursing workforce environment, and a lack of qualified nurse preceptors (Barnett et al., 2008; Leners et al., 2006). It is therefore vital that the nursing education sector and undergraduate students maximise learning opportunities during clinical placements.

Two factors identified as key determinants of student satisfaction of clinical learning experience are quality clinical facilitator support and the available range of clinical learning opportunities (Courtney-Pratt et al., 2012; Lewin, 2007). Both of these dimensions are measured in a recently published abbreviated Clinical Learning Environment Inventory (CLEI19) that assessed students' satisfaction with both clinical facilitators' support of learning and the clinical facility (Salamonson et al., 2011). Nevertheless, one of the limitations of a standardised scale is the inability to explicate explanations for participants' ratings. The addition of open-ended questions is likely to provide richer information, and perhaps insights into the rationales for students' ratings, as well as elaboration on the type of support (or lack thereof) students received from clinical facilitators and clinical staff, and information on student views of the quality of clinical placements (Agamy and Alhakim, 2013; Grebennikov and Shah, 2013). 


\section{Background}

Over the last decade, the widening participation agenda in higher education has been at the core of education policy in the United Kingdom, the United States and Australia, in an attempt to redress the educational inequality between social classes and under-represented minority groups (James, 2007; Jones and Thomas, 2005; Kettley, 2007). In Australian universities, the increasing number of nursing students brings an expanding diversity, including those for whom English is an additional language, as well as those who are spending a substantial amount of time participating in paid work whilst undertaking their nursing studies (Rochford et al., 2009; Salamonson et al., 2012).

Although a number of studies have explored the contribution of the clinical facility and supervisor to student satisfaction and quality of clinical placement (Courtney-Pratt et al., 2012; Henderson and Tyler, 2011; Lewin, 2007; Salamonson et al., 2011), few studies have explored how students' demographic characteristics may affect the perceived quality of clinical placements. This study is timely given the increasing diversity of students and the impact of differing demographics on learning styles, communication skills and interpersonal relationships. For instance, students from culturally and linguistically diverse backgrounds have been reported to have different learning styles to Australian-born, English speaking students (Chan, 2003). These students are more likely to employ didactic learning techniques, showing less appreciation for problem-based and participative learning; they are also less likely to question teachers or make appointments with them due to concepts of respect and maintaining face (Jeong et al., 2011). Clinical placements provide a unique and complex learning environment that is very different to the university classroom setting. This complexity challenges students to continue to learn whilst being in an unfamiliar 
environment. Therefore it is important to determine how diverse student groups perceive the quality of the complex clinical learning environment.

This study sought to explore students' perceptions of their clinical learning environment by combining quantitative survey results with students' comments to open-ended survey questions. In particular, the study sought to address the following research questions:

1. How satisfied are nursing students with their clinical placement, and what aspects of their clinical placement do they find most satisfying, and most challenging?

2. Are there any socio-demographic group differences in nursing students' feedback of their clinical facilitators and the clinical facility?

\section{Methods}

Data presented in this paper are part of a larger study. Elsewhere, we have published findings in relation to nursing students' experiences of adversity and negative workplace cultures, and tested the psychometric properties of a revised instrument used to assess students' perception of their clinical learning environment (Jackson et al., 2011; Salamonson et al., 2011). This paper reports a later phase of this mixed method longitudinal study of the Clinical Experiences of Nursing Students (CENSUS) at four Australian universities.

\section{Participants}

Students enrolled in the Bachelor of Nursing (BN) program within four Australian universities were invited to participate in this online survey. These students were informed about the study using flyers, information on course websites, and verbally in their oncampus class sessions. Following clinical placements, a reminder email was sent to all eligible students. Participation involved students completing an online survey about their experiences during their recent clinical placement. The survey comprised of demographic 
items, including language spoken, employment status, age and gender, as well as the 19item Clinical Learning Environment Inventory (CLEI-19) and two open-ended questions (Salamonson et al., 2011). The two open-ended questions were:

i) From your most recent clinical placement tell us what was the most challenging aspect of the clinical placement?

ii) From your most recent clinical placement tell us what was the most satisfying aspect of the clinical placement?

\section{Clinical Learning Environment Inventory (CLEI-19)}

The 19-item Clinical Learning Environment Inventory (CLEI-19) is a validated scale (Salamonson et al., 2011) derived from the 42-item CLEl developed by Chan (2002). The 19items explore students' perceptions of their experience and are comprised of 7 items from the satisfaction domain, 7 items from the personalisation domain, and 5 items related to the clinical facilitator. Nine of the items are negatively worded and the remaining 10 are positively worded. The CLEI-19 uses a Likert scale from strongly agree (5) to strongly disagree (1) for each related statement. Consistent with Chan's (2002) scoring, omitted or invalid answers are scored as 3. The total scores on the CLEI-19 range between 19 and 95, with lower scores representing a less positive perception of the clinical learning environment.

\section{Validity, reliability and rigour}

To enhance rigour in the qualitative data analysis, responses to the open-ended questions were studied independently by two researchers (JM \& KP) and the key clusters of positive and negative comments of the two dimensions of the CLEI-19 identified. Differences in the coding and classification of key themes were discussed and resolved by consensus. 


\section{Factorial validity and reliability of CLEI-19}

The Kaiser-Meyer-Olkin Measure of sampling adequacy was 0.91 suggesting the correlation matrix of the CLEI-19 items was suitable for factor analysis. The scree plot indicated that the optimal number of factors to be extracted was two (Eigenvalues of 8.6 and 2.9 respectively), accounting for $60.53 \%$ of total item variance. Using exploratory factor analysis procedure, principal component analysis with Varimax rotation yielded the same two-factor solution as that previously reported (Salamonson et al., 2011). Component loadings ranged from 0.56 to 0.79 for the 12 -item 'Clinical Facilitator Support of Learning' dimension, and from 0.76 to 0.87 for the 7-item 'Satisfaction with Clinical Placement' dimension. Cronbach's alpha for the overall CLEI-19 was 0.92, 0.91 for the 'Clinical Facilitator Support of Learning' subscale, and 0.92 for the 'Satisfaction with Clinical Placement' subscale.

\section{Ethical considerations}

By submitting the survey responses, students accepted that they had read the study information sheet and consented to participate in the study. Students were clearly informed that their participation in the survey was both anonymous and voluntary. The conduct of the study was approved by each of the relevant University Human Research Ethics Committees.

\section{Data analysis}

Survey data was downloaded from the Qualtrics ${ }^{\circledR}$ online platform. Quantitative data were analysed using SPSS Version 21 and qualitative data were imported into QSR NVivo Version 10. The CLEI-19 was analysed using descriptive statistics. Principal component analysis (PCA) was used to determine the dimensionality, and Cronbach's alpha coefficient was used to determine the internal consistency of the tool. Pearson's chi-square, Mann-Whitney and Kruskal Wallis tests were used to test for group significances. Logistic regression analysis 
was used to determine socio-demographic predictors of high CLEI-19 scores. A value of $P<$ 0.05 was considered to be statistically significant.

Qualitative data were analysed and categorised into positive and negative comments using the two dimensions of the CLEI-19: 'Satisfaction with clinical placement' and 'Clinical facilitator support of learning' as the framework. Two experienced nursing educators (JM \& $\mathrm{KP}$ ) independently scored each of the categorised comments on a 5-point scale, from 1 (most negative) to 5 (most positive). Responses to each of these comments were analysed using Cohen's Kappa to compute the adjusted proportion of agreement ( $\kappa$ ), a measure of the proportion of agreement that was not attributed to chance. A Kappa value of 0.61 to 0.80 indicates substantial and a value above 0.80 indicates near perfect agreement (Landis and Koch, 1977).

\section{Results}

From June 2010 to February 2012, nursing students from the four participating institutions were given access to the survey site. During the study period 222 (4.3\%) online surveys were submitted. Of these, 213 (95.9\%) were completed surveys. Approximately one-quarter ( $n=$ 52) of participants were in Year 1, 38\% $(n=80)$ in Year 2 and 38\% $(n=81)$ in Year 3. The mean age of participants was 32.5 years (SD: 10.6), and 93\% were female. Over threequarters ( $n=162$ ) spoke only English at home and nearly half of the participants $(n=103)$ were engaged in term-time health-related employment (Table 1).

\section{Quantitative results}

\section{Socio-demographic differences and level of nursing education}

We compared socio-demographic differences of participants with year of enrolment in their nursing studies. Approximately $52 \%(n=27)$ of first year participants, $60 \%(n=48)$ of second 
year participants and $75 \%(n=61)$ of third year participants were engaging in term-time paid work $(p=0.016)$. No other statistically significant group differences were detected.

\section{Group differences in total CLEI-19 scores and subscale scores}

Table 2 shows a group comparison of total CLEI-19 and subscale scores and English language usage, and the types of paid (none, non-health and health-related) employment of the participants. Although those with English as an additional language (EAL) were less satisfied with the clinical learning environment, as indicated by the mean CLEI-19 score (72.24 versus $77.01, p=0.007)$, this lower rating was predominantly due to their dissatisfaction with 'clinical facilitator support of learning' (Table 2). In relation to paid work, although there was no statistically significant group difference in the overall mean CLEI-19 scores between the three different employment statuses (i.e. non-in paid work / non-health-related / healthrelated), those who were in health-related employment were the least satisfied with the clinical placement (mean: 27.18 versus 29.01 for those not in paid work; $p=0.037$ ).

\section{Predictors of high CLEI-19 scores}

Using backward conditional method, logistic regression analysis yielded only one variableEnglish-speaking only-that was a statistically significant predictor of high CLEI-19 (i.e. >76 median score; adjusted odds ratio: $1.99,95 \% \mathrm{Cl}: 1.03$ to 3.82 ). Controlling for year of enrolment in the nursing program, this accounted for $4.6 \%$ of the variance (Nagelkerke's $R^{2}$ $=0.046)$. The chi-square statistic of Hosmer-Lemeshow goodness-of-fit test was $4.191(d f=$ $2, p=0.123)$ indicating good model fit.

\section{Qualitative findlings}

The length of responses to the two open-ended questions varied from 1-600 words.

Qualitative data were categorised into positive and negative comments using the two 
dimensions of the CLEI-19: 'Satisfaction with clinical placement' and 'Clinical facilitator support of learning' as the framework (i.e. four categories). Within the 'satisfaction with clinical placement' dimension, qualitative data were further grouped into seven positive and six negative comment categories. Within the 'clinical facilitator support of learning' dimension, qualitative data were grouped into one positive and three negative comment categories (Table 3). Of the four categories, the Kappa values were as follows: a) 'Satisfaction with clinical placement - Positive', 0.65 ; b) 'Satisfaction with clinical placement Negative', 0.63; c) 'Clinical facilitator support of learning - Positive', 0.79; and d) 'Clinical facilitator support of learning - Negative', 0.94. Based on a total of 279 comments, these Kappa values indicate substantial to near perfect agreement.

\section{Satisfaction with clinical placement dimension}

Within the 'Satisfaction with clinical placement' dimension, positive comments typically referred to making a difference by providing patients with good nursing care. A typical positive response is provided below:

Communicating with and helping patients. This was my first hospital placement and the first opportunity, so far in my degree, to genuinely feel like I was making a difference in the health and well-being of my patients. (Participant 35, native Englishspeaking student who worked part-time as pharmacy assistant)

A common category among the negative comments within the 'satisfaction with clinical placement' dimension was 'nursing clinicians' disinterest in teaching or the lack of time to teach nursing students.' One comment clearly illustrates this:

The most challenging aspect was trying to get some experience with the RNs at the placement, it felt like we were unwanted and nobody who worked there were notified that we were coming (Participant 173, native English-speaking student, not in paid employment). 


\section{Clinical facilitator support of learning}

The responses regarding participants' views of the clinical facilitators reflected a fairly even balance of positive and negative experiences. The positive comments about clinical facilitators focused on learning opportunities being accessible and positive. As one participant wrote:

The clinical facilitators from all of my placements have been very good and done their best to make the best of the situation. Many times, the only opportunity I had to do the tasks I was sent to practice was when the facilitator came in to the ward and demanded we have an opportunity to do them together. They have all had my best interests in mind and have challenged me and I have learned a lot from them (Participant 114, native English-speaking student, not in paid employment).

Some students reported challenges around the ways in which facilitators supported their learning needs. The majority of negative responses regarding facilitator support reflected a teacher focus rather than a focus on the learning needs of students. As one participant commented:

The facilitator told me and the other student to have lunch after the orientation and meet her in the library. So we went and at around 2:30pm ... we were asked what we did in the library, we read few journals about [schizophrenics] because these are the cases in the ward we are in, but the facilitator discussed borderline personality. In my opinion we should have focused on [schizophrenia] because we are in a ward [with patients who have schizophrenia], not a single patient have [sic] borderline personality. Not relevant at all. (Participant 87, EAL student, not in paid employment).

\section{Data integration}

Interestingly, some quantitative results and qualitative data appeared to portray conflicting messages. Although the quantitative data indicated that students with EAL were less satisfied with the clinical facilitator (Table 2), this finding was not borne out in the 
qualitative data. For instance, seven of the nine comments related to the lack of engagement of the clinical facilitator' category were made by native English-speaking students (Table 4). Similarly, although the quantitative data suggested that those who were engaged in health-related work were less satisfied with the clinical placement (Table 2), the frequencies of negative comments made by those in health-related work were no more than those not participating in paid work or those in non-health-related work.

\section{Discussion}

Students with EAL were less satisfied with the clinical learning environment as indicated by the CLEI-19 scores; nevertheless, the qualitative data showed that native English speakers provided more negative responses regarding their placement. An explanation for these seemingly conflicting findings could be that students with EAL lacked sufficient confidence to provide written data in response to the open-ended comments. Previous research findings among culturally diverse students suggest that learning and teaching can be challenged by cultural and language barriers (Pitkajarvi et al., 2013).

It could also be that EAL students were less satisfied with the clinical learning environment, as reflected by the lower mean CLEI-19 score, because clinical facilitators may be less prepared to accommodate the specific learning needs of this group. In Australia, the changing demographics of the student population, with increasing numbers of students from non-English speaking backgrounds, create particular challenges for nurse educators and health care institutions (Parker and McMillan, 2007).

Clinical facilitators often have inadequate preparation for the role (Omansky, 2010) or experience workload pressures that limit their capacity for effective clinical teaching and 
can impact on the depth of learning opportunities for students (McCarthy and Murphy, 2010; Omansky, 2010). Additionally, much learning in the clinical setting is dialogic and informal, with a rich exchange of experiential knowledge between the student and experienced clinician (Finnerty and Collington, 2013). It is feasible that clinical facilitators may be less skilled in meeting the situated learning in practice needs of EAL students, which may help explain why these students were less satisfied than students who were native English speakers.

Another trend that was made evident through further analysis of the data was the significantly lower satisfaction of working students when compared to non-working students, particularly with those working in a health-related field. Previous research may offer several explanations for this finding. For example, it has been shown that the longer hours a student works in a week, the more negative the impact on their overall university experience (Rochford et al., 2009). Studies also report that there is a distinct conflict of interest as students try to balance time for work and study, which could contribute to higher stress levels and an overall lower perceived quality of university experiences (Nicholl and Timmins, 2005; Watts and Pickering, 2000). During clinical placement, financial stress on students can increase, particularly in rural placements, which can further exacerbate this conflict of interest (Cuthbertson et al., 2004; Schofield et al., 2009). It is possible that these were also factors in our study; however, collecting data that could explain the lower levels of satisfaction among working students would need to be further explored in future work. In the interpretation of the results of this study, several limitations need to be considered. Out of a population of over 4000 nursing students, only 213 (5.3\%) completed the survey. Due to this limited sample size, care needs to be taken in the interpretation of these data. 
Nevertheless, the mixed methods design of this study that combined participants' responses to standardised scales and responses to open-ended questions provided greater insight into students' clinical experiences.

\section{Conclusion}

This study set out to explore how satisfied nursing students were with the quality of their clinical placement, and which aspects they found most - or least - satisfying. Overall, participants were generally satisfied with their clinical placement as indicated by their CLEI scores. Participants with EAL were less satisfied with their clinical placement experience, in particular with the support of their learning by their clinical facilitators. However, it was those with English as their first language who were more likely to express dissatisfaction with their clinical placement in the open-ended comments. These findings suggest further research utilising either individual or focus group interviews would be useful to gain an understanding of the reasons for student dissatisfaction with their clinical placement experience.

One of the more interesting findings to emerge from this study is that students who were employed in health-related work were actually less satisfied with their clinical placement than those in non-health related employment, or those not in paid work. More research is needed to better understand the reasons for this, particularly given the commonly held belief that nursing students employed in health settings benefit from skills acquisition and are better prepared for transition to graduate practice. 


\section{References}

Agamy, E., Alhakim, A., 2013. Monitoring the student experience: Case study of the University of Sharjah. Enhancing Student Feedback and Improvement Systems in Tertiary Education, 101.

Aiken, L. H., Cheung, R. B., Olds, D. M., 2009. Education policy initiatives to address the nurse shortage in the United States. Health Affairs 28 (4), w646-w656.

Barnett, T., Cross, M., Jacob, E., Shahwan-Akl, L., Welch, A., Caldwell, A., et al., 2008. Building capacity for the clinical placement of nursing students. Collegian 15 (2), 55-61.

Chan, D., 2002. Development of the clinical learning environment inventory: Using the theoretical framework of learning environment studies to assess nursing students' perceptions of the hospital as a learning environment. Journal of Nursing Education 41 (2), 69.

Chan, D. S. K., 2003. Validation of the Clinical Learning Environment Inventory. Western Journal of Nursing Research 25 (5), 519-532.

Courtney-Pratt, H., FitzGerald, M., Ford, K., Marsden, K., Marlow, A., 2012. Quality clinical placements for undergraduate nursing students: a cross-sectional survey of undergraduates and supervising nurses. Journal of Advanced Nursing 68 (6), 1380-1390.

Cuthbertson, P., Lauder, W., Steele, R., Cleary, S., Bradshaw, J., 2004. A comparative study of the course-related family and financial problems of mature nursing students in Scotland and Australia. Nurse Education Today 24 (5), 373-381.

Finnerty, G., Collington, V., 2013. Practical coaching by mentors: Student midwives' perceptions. Nurse Education in Practice 13 (6), 573-577.

Grebennikov, L., Shah, M., 2013. Student voice: using qualitative feedback from students to enhance their university experience. Teaching in Higher Education 18 (6), 606-618.

Henderson, A., Tyler, S., 2011. Facilitating learning in clinical practice: Evaluation of a trial of a supervisor of clinical education role. Nurse Education in Practice 11 (5), 288-292.

Jackson, D., Hutchinson, M., Everett, B., Mannix, J., Peters, K., Weaver, R., et al., 2011. Struggling for legitimacy: nursing students' stories of organisational aggression, resilience and resistance. Nursing Inquiry 18 (2), 102-110.

James, R., 2007. Social equity in a mass, globalised higher education environment: the unresolved issue of widening access to university, University of Melbourne, Centre for the Study of Higher Education

Jeong, S. Y.-S., Hickey, N., Levett-Jones, T., Pitt, V., Hoffman, K., Norton, C. A., et al., 2011. Understanding and enhancing the learning experiences of culturally and linguistically diverse nursing students in an Australian bachelor of nursing program. Nurse Education Today 31 (3), 238-244.

Jones, R., Thomas, L., 2005. The 2003 UK government higher education white paper: A critical assessment of its implications for the access and widening participation agenda. Journal of Education Policy 20 (5), 615-630.

Kettley, N., 2007. The past, present and future of widening participation research. British Journal of Sociology of Education 28 (3), 333-347. 
Lambert, V., Glacken, M., 2005. Clinical education facilitators: a literature review. Journal of Clinical Nursing 14 (6), 664-673.

Landis, J. R., Koch, G. G., 1977. The measurement of observer agreement for categorical data. Biometrics 33 (1), 159-174.

Leners, D., Sitzman, K., Hessler, K. L., 2006. Perceptions of nursing student clinical placement experiences. International Journal of Nursing Education Scholarship 3 (1), 1267.

Lewin, D., 2007. Clinical learning environments for student nurses: Key indices from two studies compared over a 25 year period. Nurse Education in Practice 7 (4), 238-246.

McCarthy, B., Murphy, S., 2010. Preceptors' experiences of clinically educating and assessing undergraduate nursing students: an Irish context. Journal of Nursing Management 18 (2), 234244.

Nicholl, H., Timmins, F., 2005. Programme-related stressors among part-time undergraduate nursing students. Journal of Advanced Nursing 50 (1), 93-100.

Omansky, G. L., 2010. Staff nurses' experiences as preceptors and mentors: an integrative review. Journal of Nursing Management 18 (6), 697-703.

Parker, V., McMillan, M., 2007. Challenges facing internationalisation of nursing practice, nurse education and nursing workforce in Australia. Contemporary Nurse 24 (2), 128-136.

Pitkajarvi, M., Eriksson, E., Pitkala, K., 2013. Culturally diverse health care students' experiences with teaching strategies in Finland: A national survey. Nurse Education Today 33 (6), 590-595.

Rochford, C., Connolly, M., Drennan, J., 2009. Paid part-time employment and academic performance of undergraduate nursing students. Nurse Education Today 29 (6), 601-606.

Salamonson, Y., Bourgeois, S., Everett, B., Weaver, R., Peters, K., Jackson, D., 2011. Psychometric testing of the abbreviated Clinical Learning Environment Inventory (CLEI-19). Journal of Advanced Nursing 67 (12), 2668-2676.

Salamonson, Y., Everett, B., Koch, J., Andrew, S., Davidson, P. M., 2012. The impact of term-time paid work on academic performance in nursing students: A longitudinal study. International Journal of Nursing Studies 49 (5), 579-585.

Schofield, D., Keane, S., Fletcher, S., Shrestha, R., Percival, R., 2009. Loss of income and levels of scholarship support for students on rural clinical placements: A survey of medical, nursing and allied health students. Australian Journal of Rural Health 17 (3), 134-140.

Watts, C., Pickering, A., 2000. Pay as you learn: student employment and academic progress. Education+ Training 42 (3), 129-135. 
Table 1 Characteristics of participants $(n=213)$

\section{Variable}

Age, mean $(S D)$ years ( $n=213$; Range: 18 to 62 years)

$32.5(10.6)$

Sex, $n(\%)$

Female

$199(93)$

Male

$14(7)$

Year of enrolment, $n$ (\%)

Year 1

Year 2

$80(38)$

Year 3

$81(38)$

Country of birth, $n(\%)$

Australia

Born outside Australia

Enrolment classification, international student $n$ (\%)

Language spoken at home, $n(\%)$

English

$162(76)$

Other than English

16 (8)

Both English and non-English

English language acculturation scale (ELAS) score, mean (SD)

( $n=213$; Range: 5 to 25 )

First person in family to attend university, $n(\%)$

Employment status during semester, $n(\%)$

Not in paid work

Non-health-related work

Health-related work

Average hours of paid work during semester (hours/week), mean (SD)

( $n=136^{*}$; Range: 0 to 50 )

* Missing data 


\section{Table 2}

Mean and standard deviation comparison of CLEI-19 scores and related subscales

\begin{tabular}{|c|c|c|c|c|c|c|}
\hline \multirow[t]{2}{*}{ Characteristic } & \multicolumn{2}{|c|}{ Total CLEI-19 scores } & \multicolumn{2}{|c|}{$\begin{array}{l}\text { Clinical facilitator } \\
\text { support of learning }\end{array}$} & \multicolumn{2}{|c|}{$\begin{array}{l}\text { Satisfaction with clinical } \\
\text { placement }\end{array}$} \\
\hline & (mean, SD) & $\mathrm{p}$ & (mean, SD) & $\boldsymbol{P}$ & (mean, SD) & $\boldsymbol{P}$ \\
\hline \multicolumn{7}{|l|}{ English language usage } \\
\hline English only ( $n=143$ ) & $77.01(12.54)$ & 0.007 & $48.74(8.18)$ & $<0.001^{*}$ & $28.27(6.33)$ & 0.277 \\
\hline English as an additional language $(n=70)$ & $72.24(12.57)$ & & $44.47(8.94)$ & & $27.77(5.72)$ & \\
\hline \multicolumn{7}{|l|}{ Employment status during semester } \\
\hline Not in paid work $(n=77)$ & $75.87(13.37)$ & 0.098 & $46.86(9.45)$ & 0.217 & $29.01(5.40)$ & $0.037^{*}$ \\
\hline Non-health-related paid work $(n=33)$ & $78.55(13.74)$ & & $49.67(8.22)$ & & $28.88(6.80)$ & \\
\hline Health-related paid work $(n=103)$ & $74.14(11.78)$ & & $46.95(8.11)$ & & $27.18(6.33)$ & \\
\hline
\end{tabular}

$* p<0.05$

Mann-Whitney and Kruskal Wallis tests were used for tests of significance 
Table 3 Student Perception of the Clinical Learning Environment: CLEI-19 subscales and Qualitative Responses

\begin{tabular}{|c|c|c|c|}
\hline $\begin{array}{l}\text { The CLEI-19 } \\
\text { subscale }\end{array}$ & $\begin{array}{l}\text { Positive } \\
\text { or } \\
\text { Negative }\end{array}$ & Category & $\begin{array}{l}\text { Frequency } \\
\text { of } \\
\text { comments }\end{array}$ \\
\hline \multirow{15}{*}{$\begin{array}{l}\text { Satisfaction } \\
\text { with clinical } \\
\text { placement }\end{array}$} & Positive & $\begin{array}{l}\text { Making a difference by providing good } \\
\text { nursing care }\end{array}$ & 42 \\
\hline & Positive & $\begin{array}{l}\text { Scope of practice: 'In the zone' - full } \\
\text { involvement, and feeling energised }\end{array}$ & 37 \\
\hline & Positive & Positive learning experience & 35 \\
\hline & Positive & $\begin{array}{l}\text { Nursing or other clinicians' expertise, } \\
\text { approachability, and willingness to teach }\end{array}$ & 22 \\
\hline & Positive & Sense of Belonging & 19 \\
\hline & Positive & Being valued by clinical staff during clinical & 6 \\
\hline & Positive & $\begin{array}{l}\text { Appropriateness of placement for clinical } \\
\text { learning focus }\end{array}$ & 2 \\
\hline & \multicolumn{2}{|l|}{ Sub-total } & 164 \\
\hline & Negative & $\begin{array}{l}\text { Nursing clinicians' disinterest in teaching or } \\
\text { lack of time to teach nursing students }\end{array}$ & 26 \\
\hline & Negative & $\begin{array}{l}\text { Inappropriateness of placement, poor } \\
\text { alignment with clinical learning focus }\end{array}$ & 21 \\
\hline & Negative & $\begin{array}{l}\text { Scope of practice: Too narrow, bored or } \\
\text { pressured to go beyond scope of practice }\end{array}$ & 8 \\
\hline & Negative & Excessive nursing workload & 7 \\
\hline & Negative & $\begin{array}{l}\text { Distance travelled for clinical placement or } \\
\text { having to live away from home }\end{array}$ & 4 \\
\hline & Negative & $\begin{array}{l}\text { Learning in clinical environment of poor } \\
\text { nursing care }\end{array}$ & 2 \\
\hline & \multicolumn{2}{|l|}{ Sub-total } & 68 \\
\hline \multirow{6}{*}{$\begin{array}{l}\text { Clinical } \\
\text { facilitator } \\
\text { support of } \\
\text { learning }\end{array}$} & Positive & Creates a positive learning environment & 16 \\
\hline & \multicolumn{2}{|l|}{ Sub-total } & 16 \\
\hline & Negative & $\begin{array}{l}\text { Teaching approach: 'teacher-centred' rather } \\
\text { than 'student-centred' }\end{array}$ & 16 \\
\hline & Negative & $\begin{array}{l}\text { Lack of engagement, 'invisible', did not } \\
\text { facilitate the learning process }\end{array}$ & 9 \\
\hline & Negative & Unprofessional behaviour & 7 \\
\hline & \multicolumn{2}{|l|}{ Sub-total } & 32 \\
\hline
\end{tabular}


Table 4 Theme: Clinical Facilitator (Negative Comment)

Lack of engagement, 'invisible', did not facilitate the learning process

\begin{tabular}{|c|c|c|}
\hline Participant & Characteristics & Selected examples of comments \\
\hline 4 & $\begin{array}{l}\text { Australian-born, English-speaking } \\
\text { only at home }\end{array}$ & $\begin{array}{l}\text { Facilitator commented: "I don't believe I have seen enough of your work and I have completed this } \\
\text { summary with limiting information". My jaw had dropped at the remark; she had not visited my ward } \\
\text { for } 2 \text { days .... [..of a 4-day clinical]. }\end{array}$ \\
\hline 16 & $\begin{array}{l}\text { Born overseas, non-English- } \\
\text { speaking only at home }\end{array}$ & My clinical facilitator never came to see us in the ward. She was usually sitting in cafeteria. \\
\hline 22 & $\begin{array}{l}\text { Australian-born, English-speaking } \\
\text { only at home }\end{array}$ & $\begin{array}{l}\text { Facilitator never came to check on you on the ward. Just made sure you showed up and checked you } \\
\text { were there at end of night }\end{array}$ \\
\hline 33 & $\begin{array}{l}\text { Australian-born, English-speaking } \\
\text { only at home }\end{array}$ & I found my experience at my last prac challenging because our clinical teacher was very inattentive \\
\hline 154 & $\begin{array}{l}\text { Australian-born, English-speaking } \\
\text { only at home }\end{array}$ & $\begin{array}{l}\text { The facilitator made my placement nerving and unenjoyable due to the fact that he was never } \\
\text { present, and when he did show up he would stay for max } 5 \text { minutes. If he saw me with a patient doing } \\
\text { meds with supervision of a nurse he would leave the ward instead of coming over and seeing what i } \\
\text { was doing or how well i was doing. / he would make me and other students do large amounts of } \\
\text { research and write down information we found then make us present it to the other students. when } \\
\text { we would present our case studies and other information he would leave the group and make phone } \\
\text { calls or sit in front of us reading and sending text messages off his phone. }\end{array}$ \\
\hline 156 & $\begin{array}{l}\text { Born overseas, English-speaking } \\
\text { only at home }\end{array}$ & $\begin{array}{l}\text { Facilitator was absent for most of shift, observer her sitting in her car reading a book for most off day } \\
\text { as i could see her from my ward ..... took way too long to finish debrief as by the time we finished all } \\
\text { other staff left hospital making it unsafe to walk to our cars. }\end{array}$ \\
\hline 176 & $\begin{array}{l}\text { Australian-born, English-speaking } \\
\text { only at home }\end{array}$ & $\begin{array}{l}\text { Having never worked in health care before, getting used to the environment as well as new staff } \\
\text { everyday took me little bit to adjust. If the clinical facilitator had been able to be around a bit more it } \\
\text { may have been different. }\end{array}$ \\
\hline 196 & $\begin{array}{l}\text { Born overseas, spoke both English } \\
\text { and non-English at home }\end{array}$ & $\begin{array}{l}\text {.... dealing with the clinical facilitator, the whole week our facilitator was late, didn't turn up on } \\
\text { Wednesday.... BTW, she has her mobile phone on at all times, during checking of paperworks [sic] the } \\
\text { first day as well as during debriefing and handovers. }\end{array}$ \\
\hline 209 & $\begin{array}{l}\text { Australian-born, English-speaking } \\
\text { only at home }\end{array}$ & $\begin{array}{l}\text { The only conversation she [the facilitator] was interested in with me was talking about beauty therapy } \\
\text { as I told her I was a Beauty Therapist before I started my Bachelor of Nursing course at Uni... }\end{array}$ \\
\hline
\end{tabular}

